\title{
ESTUDO COM PSICÓLOGOS ESCOLARES: Ações e desafios
}

\author{
A study on educational psychologists: Practices and challenges
}

\author{
Maria da Apresentação Barreto ${ }^{[a]}$, Paula Ângela Fernandes Ribeiro Dantas Calafange ${ }^{[\mathrm{b}]}$, \\ Zilanda Pereira de Lima ${ }^{[c]}$
}

\begin{abstract}
[a] Psicóloga e Doutora em Educação, docente da Faculdade Natalense para o Desenvolvimento do Rio Grande do Norte (FARN), Universidade Potiguar, Parnamirim, RN - Brasil, e-mail: apresentacao@unp.br

[b]Paula Ângela Fernandes Ribeiro Dantas Calafange, graduada em direito e aluna do Curso de Psicologia da Faculdade Natalense para o Desenvolvimento do Rio Grande do Norte (FARN), Parnamirim, RN - Brasil.

${ }^{[c]}$ Zilanda Pereira de Lima, aluna do Curso de Psicologia da Faculdade Natalense para o Desenvolvimento do Rio Grande do Norte (FARN), Parnamirim, RN - Brasil.
\end{abstract}

\begin{abstract}
Resumo
A atuação profissional dos psicólogos escolares é marcada por numerosos desafios que oscilam entre a formação acadêmica e os dilemas vivenciados entre as ações desenvolvidas e as ações esperadas. Esses desafios vão configurando a identidade profissional e apontando uma diversidade de ações e perspectivas de inserção nas escolas. O presente estudo buscou identificar as ações que estão sendo empreendidas e os desafios enfrentados pelos psicólogos nas instituições de ensino na cidade de Natal, RN. A pesquisa foi qualitativa e os dados foram coletados através de uma entrevista semiestruturada aplicada entre os psicólogos escolares. Os resultados revelaram uma diversidade de ações em desenvolvimento, agrupadas em atividades direcionadas aos alunos, aos pais, aos professores e à instituição escolar. A diversidade de desafios revela questões interligadas à construção de identidade, às condições de trabalho e à formação, que não foi suficiente para atender às exigências do contexto escolar. Além de ter tido a oportunidade de conhecer, de perto, a atuação desse profissional, o estudo ainda permitiu tecer reflexões sobre a importância de uma formação profissional sintonizada com as necessidades de cada contexto e alicerçada em conhecimentos capazes de auxiliar na compreensão e intervenção não apenas na instituição escolar, mas nos diversos contextos educativos.
\end{abstract}

Palavras-chave: Psicólogo escolar. Práticas educativas. Formação profissional. 


\begin{abstract}
The work of educational psychologists is marked by challenges that oscillate from academic degree to dilemmas between what has been developed and what is expected. These challenges have been contributed to shape the professional's identity and point to perspectives of insertion in schools. The aim of this study is identify which actions have been applying and what kind of challenges the educational psychologists have to face nowadays. Our study was based on a qualitative research and the data were collected by semi-structured interviews applied to educational psychologists. Our results show us a variety of things which are being done with the focus on students, parents, teachers and institutions. The existence of different challenges have demonstrated questions closely related to construction of identity, work conditions and formation what does not enough to prepare facing the demands of the school context. Moreover, the study not only give us the opportunity to understand the knowledge in the work of these professionals, but also make us to reflect about how important is the academic degree to be syntonized with the real needs of the community and also it could be rooted in knowledge that will help them in their work as to be applied in different educational contexts.
\end{abstract}

Keywords: Educational psychologist. Educational practices. Academic degree.

\section{INTRODUÇÃO}

Este artigo socializa os resultados de uma pesquisa que objetivou identificar as ações e os desafios que permeiam o cotidiano dos psicólogos escolares na cidade de Natal, / $\mathrm{RN}^{1}$.

Desde o seu início, a atuação do psicólogo escolar tem sido permeada por questionamentos e desafios. Discorrendo sobre as origens e o desenvolvimento da Psicologia escolar, Pfromm Neto (2001) refere que inicialmente essa área tinha o compromisso ou intenção de promover o bem-estar e o desenvolvimento saudável das crianças em idade escolar. Hoje, já esboça uma preocupação em ampliar sua abrangência para adultos da escola, como pais, professores e comunidade. Os desafios que se interpõem a essa atuação perpassam a formação dos psicólogos escolares, as condições de trabalho que lhes são oferecidas, as exigências feitas pelas instituições, a visão de sociedade que norteia a prática e as possibilidades de intervenções que saiam do plano apenas curativo, culminando com ações promotoras de saúde, satisfação e prazer relacionados com o processo de formação humana e cognitiva.
Em se tratando das perspectivas para o futuro da psicologia escolar, Novaes (2001) afirma que os profissionais que atuam nessa área serão cada vez mais cobrados a se posicionar quanto a realidade social e a contribuir para o desenvolvimento das potencialidades humanas. A autora elenca uma série de desafios relacionados com a marginalização, a violência urbana, a desestabilização familiar, a falta de valores éticos e morais, dentre outros que se refletem nas instituições de ensino e nas relações educativas, o que exige, dos profissionais que atuam com educação, uma reflexão crítica acerca desses desafios, um posicionamento e uma intervenção capazes de contribuir para a transformação dessa realidade. A autora, discorrendo explicitamente sobre o papel do psicólogo escolar, afirma:

No futuro, diante das transformações sociais e culturais, o psicólogo escolar ajudará os agentes educativos e os alunos a conviverem com a desordem, a contradição e a ambiguidade presentes, a transcender as dualidades, resistindo às tendências desestabilizadoras dos sistemas, acreditando que o impossível nada mais é do que um possível viável e, ao mesmo tempo, valorizando seus conhecimentos e acervos culturais existentes (NOVAES, 2001, p. 64).

\footnotetext{
1 A pesquisa foi desenvolvida por alunos do Curso de Psicologia da Faculdade Natalense para o Desenvolvimento do Rio Grande do Norte, no ano de 2006, quando cursavam a disciplina Psicologia e Educação.
} 
Desse modo, levando em consideração as ideias expostas, podemos dizer que uma das maiores contribuições que podem ser dadas pelo psicólogo consiste na preparação para vivermos ou convivermos com as incertezas, o imprevisível e as possibilidades. Nessa perspectiva, é prudente apoiarmo-nos nas ideias de Morin (2003) a respeito das possíveis contribuições da educação neste início de século XXI. Esse pensador alerta-nos para a imprevisibilidade e convida-nos a assumir uma postura mais investigativa e menos dogmática. As certezas devem ser questionadas, as verdades postas em debate: ordem e desordem, afirmação e contradição dialogam na construção de novas possibilidades. A educação veiculada nas escolas e noutros grupos informais não pode deixar de considerar a velocidade com que as informações são divulgadas. Ainda assim, a estas não podemos ficar presos. É preciso interpretá-las e dar-lhes um novo sentido. É a necessidade do conhecimento pertinente do qual nos fala o autor. Conhecimento esse que nos possibilite responder aos problemas que ameaçam nosso bem-estar, nossa qualidade de vida e nossa felicidade. O impossível é apenas uma questão de visão ou de postura que adotamos diante dos desafios.

Sendo assim, é impossível deixarmos de comparar o que é solicitado do psicólogo com a formação que lhe é oferecida durante a graduação. Desde o início dos cursos de graduação em Psicologia, aqui no Brasil, constatou-se um acentuado direcionamento da formação para a área clínica. Com a emergência de outros espaços de atuação, ampliados especialmente a partir da década de 1980, as empresas, as escolas, os hospitais e as comunidades passaram a requerer a presença e a intervenção desse profissional, mas a formação acadêmica não deu conta de acompanhar as novas demandas. As situações, necessidades e os espaços diferenciados foram sendo ocupados por pessoas que tiveram formação igual, única, direcionada e moldada pelo modelo clínico, de atendimento individual e que, muitas vezes, isolava o sujeito do seu contexto social e comunitário.

Uma vez que este estudo tem seu foco na atuação do psicólogo no contexto escolar, delimitamos os objetivos que nortearam a investigação. Como objetivo geral, nos propusemos a conhecer as ações e os desafios enfrentados pelos psicólogos nas instituições de Natal. Os objetivos específicos ficaram assim delimitados: identificar as escolas que contam com o psicólogo escolar no seu quadro de profissionais; descrever as ações desenvolvidas pelos psicólogos; enumerar as dificuldades referentes à sua atuação; e refletir sobre a formação profissional frente à realidade descrita pelos psicólogos.

\section{METODOLOGIA}

\section{O percurso investigativo}

Sendo uma pesquisa qualitativa, buscou aprofundar o conhecimento da realidade exposta pelos psicólogos escolares. O foco do estudo esteve centrado nas ações desenvolvidas por esses profissionais, suas dificuldades, bem como na formação que tiveram para ocupar a função atual.

A delimitação da amostra foi feita da seguinte forma: inicialmente, 80 alunos do curso de psicologia da FARN foram divididos em subgrupos de cinco componentes; logo em seguida, visitaram 24 escolas na cidade de Natal, sendo 18 da rede particular de ensino. As outras seis escolas - municipais ou estaduais - não tinham em seu quadro funcional a presença do psicólogo escolar. Nas escolas particulares identificaram as que tinham psicólogos, e, mantidos os contatos preliminares, pediram a sua colaboração como participantes do estudo. Foram identificadas 15 escolas que tinham psicólogos e em todas elas houve colaboração para a pesquisa proposta.

A coleta de dados realizou-se através de um roteiro de entrevista semiestruturada elaborada após aprofundamento teórico do tema, bem como orientações a respeito da construção de instrumento de pesquisa e sua correlação com os objetivos desejados. Cada grupo tinha liberdade na proposição das questões, contanto que estivessem coerentes com os objetivos propostos. A aplicação aconteceu no período de 16 a 25 de maio de 2006 .

Os dados coletados, além deste artigo, também geraram relatórios de pesquisa elaborados por cada subgrupo, relatórios esses que foram apresentados, discutidos e avaliados como atividade geradora de conhecimento para os acadêmicos de Psicologia. 


\section{RESULTADOS}

\section{Psicólogos em atuação}

O estudo nos colocou em diálogo com 15 psicólogos que atuam em escolas particulares cidade de Natal, valendo ressaltar que $80 \%$ dessas escolas atendem a alunos da educação infantil ao ensino médio.

A constatação da presença de psicólogos somente em escolas particulares já nos remete à reflexão de que, embora estejamos diante de uma área de atuação que internacionalmente tem, praticamente, mais de um século (Salvador, 2000), aqui, no Brasil e, mais especificamente, em Natal, isso ainda constitui um privilégio. E se levarmos em conta que na rede pública de ensino, esse profissional não executa atividades direcionadas somente às escolas, podemos inferir quão limitada, em termos de priorização, deve ser sua prática nessas escolas.

Observamos ainda que, mesmo no ensino particular, algumas escolas contratam o psicólogo com uma carga horária bastante reduzida. Essa realidade ocasiona sobrecarga de atribuições e limita a eficácia de suas ações.

Outros dados foram organizados através de figuras que permitem visualizar as principais ações e os principais desafios experimentados por esse profissional, possibilitando umapercepçãomais abrangentedo estudo.

\section{AÇÕES DESENVOLVIDAS PELOS PSICÓLOGOSESCOLARESEM NATAL}

\begin{tabular}{|c|c|c|}
\hline ALUNOS & PAIS & PROFESSORES \\
\hline $\begin{array}{l}\text { - Indentificação das dificuldades e } \\
\text { possibilidades de aprendizagem } \\
\text { - Encaminhamento para atendi- } \\
\text { mentos clínicos } \\
\text { - Orientação vocacional } \\
\text { - Avaliação psicodiagnóstica } \\
\text { - Atendimento individual }\end{array}$ & $\begin{array}{l}\text { - Palestras sobre temas que } \\
\text { contribuam para a formação } \\
\text { dos alunos } \\
\text { - Orientaçãoindividuale familiar }\end{array}$ & $\begin{array}{l}\text { - Planejamento das ações } \\
\text { - Qualificação } \\
\text { - Orientações para que desen- } \\
\text { volvam a sensibilidade ante as } \\
\text { limitações e o ritmo individual } \\
\text { do aluno } \\
\text { - Flexibilidade } \\
\text { - Atendimento individual }\end{array}$ \\
\hline
\end{tabular}

\section{INSTITUIÇÃO}

- Participação nas reuniões pedagógicas

Elaboração de projetos com outros profissionais da instituição

Seleção de funcionários

- Atendimentos individuais

FIGURA 1 - Ações desenvolvidas pelos psicólogos em Natal 
Outrossim, temos claro que a atuação do psicólogo acontece de forma sincronizada e articulada com as necessidades que emergem. Neste estudo, para efeitos de compreensão e visualização, apresentamos separadamente o que foi dito em relação às suas práticas junto aos alunos, pais, professores e à instituição em geral. Na apresentação dessas ações nos reportamos às ideias de Novaes (2001) a qual chama a atenção dos psicólogos para que desenvolvam a versatilidade e consigam trabalhar com outros profissionais da educação que também se preocupem com a transformação social. Ela nos chama também a atenção para irmos além das intervenções e propormos ações promotoras e facilitadoras da convivência humana.

De modo geral, foram bastante evidenciados o compromisso e a responsabilidade dos profissionais que estão atuando nas escolas. Nas suas falas, notou-se a preocupação em atender às solicitações institucionais, muitas vezes ainda bastante pautadas numa perspectiva curativa, sem deixarem de evidenciar a elaboração de projetos e trabalhos multidisciplinares que colaborem com o processo ensino-aprendizagem, aperfeiçoamento dos profissionais da educação e respeito às limitações e à individualidade dos envolvidos.

Em relação aos alunos, o profissional de Psicologia trabalha no sentido de ampliar as suas possibilidades de aprendizagem, através da identificação dos conteúdos que obstaculizam o avanço do ensino, contribui para o planejamento de ações pedagógicas adequadas aos seus interesses. Trabalha com orientação vocacional, avaliação psicodiagnóstica, bem como encaminhamento ao atendimento clínico, quando necessário. Comparando essas ações com os primórdios da Psicologia aplicada à escola, apoiados nos escritos de Correia e Campos (2004), constatamos os avanços construídos por esses profissionais ao longo dos anos. Se o início foi marcado por uma perspectiva individualista, psicométrica, seletiva e adaptativa, agora percebemos uma preocupação em respeitar a individualidade, incluir as diferenças e planejar ações que contribuam para a superação de limitações e o desenvolvimento da criatividade e das potencialidades latentes.

Os pais são atendidos através da promoção de palestras sobre temas atuais e até controversos, como os que dizem respeito à sexualidade, relação pais/filhos, violência doméstica, dentre outros. Fazem os psicólogos ainda um trabalho de atendimento e orientação a algumas famílias e, quando necessário, o encaminhamento para que as crianças e adolescentes sejam acompanhados através do atendimento clínico. Aqui são requeridas habilidades bem específicas que instrumentalizem o psicólogo na ação. Del Prette e Del Prette (2001), discorrendo sobre as habilidades envolvidas na atuação do psicólogo escolar, mencionam a importância das habilidades interpessoais.

O valor das habilidades interpessoais é comprovado em todas as esferas de atuação, especialmente no atendimento aos pais. Nossa experiência comprova - e os participantes da pesquisa confirmaram - que esta habilidade é imprescindível. Alguns pais chegam para o atendimento trazendo outras preocupações do cotidiano e ainda se sentem discriminados por terem sido convocados para um atendimento com o psicólogo. Nessa hora, as habilidades interpessoais terão que ser mobilizadas a fim de sensibilizá-los para o mais importante: a condução do processo educacional dos seus filhos. A questão da discriminação se assenta na imagem distorcida, construída por alguns, de que o psicólogo atende a pessoas desajustadas, desequilibradas e sem saúde mental. Com esta visão, fica difícil encarar o atendimento como um momento construtivo e educativo; ainda assim, os participantes deste estudo mencionaram experiências construtivas em diversas escolas.

Também os professores têm no psicólogo um bom suporte para a melhoria do seu desempenho, numa postura de maior flexibilidade e aceitação dos alunos, respeitando os seus limites, e promovendo a inserção de todos, na aceitação do ritmo individual dos mesmos. Recebem, também, orientação no tocante ao planejamento das aulas, são apoiados quando explicitam a necessidade de abordar temas relevantes à formação dos alunos. São orientados para mobilizarem os alunos a pensar de forma responsável, o que, invariavelmente, promove uma visível motivação dos discentes, resultando numa melhor e maior participação nas aulas.

A preocupação com a formação docente, de acordo com Salvador (2001) e Correia e Campos (2004), está nas origens da Psicologia escolar. Se, no passado, esteve voltada prioritariamente para o preparo técnico dos profissionais, ensejando a adoção de uma perspectiva eminentemente experimentalista, atualmente, de acordo com os dados da pesquisa, já explicita ações em que o 
profissional de Psicologia se coloca como interlocutor dos professores e outros profissionais da educação. A perspectiva de atuação é dialógica, contribuindo, inclusive, para a discussão dos fatores que desencadeiam e reforçam a ansiedade na profissão docente.

Destarte, tratando da intervenção que deve ser feita, junto aos professores, para enfrentar a ansiedade desencadeada nas suas ações, Picado (2005) fala que a escola deve planejar a criação de espaços de escuta em que os professores se sintam apoiados. Este estudo com psicólogos, que atuam em instituições educacionais na cidade de Natal, revela profissionais que são interlocutores dos professores, dialogam e trocam ideias que favorecem as ações docentes. Esta forma de atuar, provavelmente, contribui para amenizar a ansiedade desencadeada no cotidiano.

Institucionalmente ainda são solicitados a desenvolver atividades, como seleção de funcionários, atendimento individual, aplicação de testes, proferimento de palestras nas reuniões pedagógicas, elaboração de projetos de trabalho, assessoria na qualificação dos profissionais envolvidos na educação, avaliação de desempenho, entre outras. Estas solicitações requerem conhecimentos mais amplos de outras áreas da Psicologia, legitimando o que nos diz Almeida (2001) a respeito da necessidade de sairmos de uma mentalidade que separa e reduz os conhecimentos para uma mentalidade que articula e une como forma de responder aos desafios que a realidade nos impõe. Também nos revelam da importância de uma formação abrangente, que subsidiem os formandos da Psicologia para atuarem com mais segurança e respaldo teórico.

\section{Dificuldades na ação}

Responder cotidianamente às ações requeridas de um psicólogo escolar significa lidar com situações adversas. Os desafios se presentificam nas questões referentes à definição da identidade profissional, às condições de trabalho e à incompatibilidade entre a formação recebida e as ações requeridas. A figura que segue esboça um pouco dessa realidade.

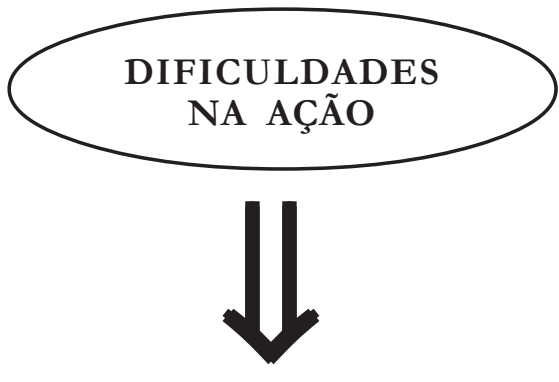

Indefinição quanto ao seu papel e às suas atribuições

- Disputa de espaço com outros profissionais da educação

Falta autonomia para algumas ações

Excesso de cobranças por parte da instituição

Carga horária de trabalho reduzida

Pouca interação com os familiares dos alunos

Formação o insuficiente para atender às solicitações

FIGURA 2 - Dificuldades na ação

Um dos desafios registrados com maior frequência foi a indefinição do papel de psicólogo. Além de não ter muita clareza quanto à sua identidade, ainda é solicitado a fazer uma plêiade de intervenções, abarcando, por vezes, atividades inerentes aos profissionais de outras áreas de conhecimento, sem deixar de considerar que também experimenta despreparo em relação ao que lhe é específico. Somos favoráveis ao trabalho interdisciplinar, mas todo profissional precisa ter clareza das suas principais atribuições e desenvolver competências específicas. Quando convocado a desempenhar múltiplos papéis, pode deixar o essencial, em função da sobrecarga de atividades e ainda perder a oportunidade de se aprofundar no desenvolvimento das competências requeridas.

Uma dificuldade já evidenciada nos escritos de Correia e Campos (2004) foi também referida pelos participantes do estudo: a indefinição de atribuições termina por desencadear uma "disputa interna" entre o psicólogo e o profissional de pedagogia. Esta dificuldade dialoga com a anterior, na medida em que a indefinição resulta numa atuação, por vezes, difusa, provocando uma "invasão" na seara dos pedagogos que, historicamente, já têm suas funções melhor delimitadas no contexto escolar. O inverso também foi confirmado; alguns psicólogos se queixaram de uma apropriação indevida do espaço do psicólogo escolar, até por pessoas que compõem o corpo 
diretivo das unidades educacionais. Alguns pedagogos desejam conduzir, de maneira bastante individualizada, projetos de orientação vocacional, orientação familiar e capacitação docente.

A delimitação de território é muito peculiar dentro de uma cultura que aprendeu a separar em partes o que desejava conhecer. Dessa forma, as áreas do conhecimento foram demarcando territórios com fronteiras rígidas. Agora, num século que apregoa a interligação, ensina Morin (2000) que é preciso reformar nossa forma de pensar para que consigamos "re-ligar" o que nos foi apresentado em separado. Nesta linha de raciocínio, trabalhar em conjunto, numa perspectiva interdisciplinar ainda, se constitui num grande desafio a ser vencido. Somos convocados a nos unir para respondermos a uma realidade que apresenta múltiplos desafios a um mesmo problema. A educação do ser humano não pode ser pensada ou tratada em áreas isoladas. Múltiplas visões e múltiplos conhecimentos para um mesmo desafio: educar para esse novo milênio.

O estudo evidencia a interligação dos desafios; assim, um outro obstáculo, dito por alguns como intransponível, é a falta de autonomia para desempenhar as atividades que lhe são inerentes. Esse obstáculo interliga-se com outra dificuldade: a cobrança excessiva por parte da instituição termina por deixar o psicólogo com uma sobrecarga de atribuições, deixando de realizar o que considera essencial. Em outras palavras: os participantes do estudo evidenciaram ter consciência do seu papel como agentes capazes de contribuir para o projeto pedagógico da escola, por intermédio de ações coletivas junto a professores, pais e alunos; entretanto, a instituição continua a lhe exigir uma atuação eminentemente individual e curativa. Por trabalhar numa instituição particular, o profissional se vê pressionado a atender o que a instituição lhe cobra.

Corresponder às expectativas faz parte de um contrato informal de trabalho, e aqui nos apoiamos em Dejours (1992) para falar da presença de um "sofrimento invisível" implícito nas relações de trabalho, e bem conhecido pelos participantes deste estudo. O trabalho é designado por diferentes conotações implícitas em seu significado, que vão além do vínculo imediato que ele mantém na realidade social. Ao mesmo tempo, é acompanhado de um campo semântico amplo e fluido que oscila entre seu aspecto penoso, ignóbil e hostil, até aspectos positivos, como atividade gratificante, honrosa, ética e criativa. No caso do trabalho dos psicólogos escolares, poderíamos enumerar diversos agentes causadores do sofrimento, resultante da série de exigências a que são submetidos, os quais, utilizando-nos de uma linguagem da matemática, se tornam inversamente proporcionais ao que é oferecido como recompensa ou reconhecimento.

A carga horária reduzida parece nos falar de várias realidades: a instituição escolar considera importante ter no seu quadro um profissional de Psicologia, mas não tem condições financeiras para contratá-lo com uma jornada que atenda às necessidades; outras têm condições, mas preferem investir em itens que expressem maior visibilidade e propaganda; outras ainda contratam com uma carga horária considerada adequada, mas para atender a um universo excessivamente grande. Nas três situações observamos um descompasso entre o que é oferecido e o que é solicitado do psicólogo. Se levarmos em conta que definição de carga horária se liga à remuneração, concordaremos em tratar-se de um fator bastante relevante para qualquer profissional.

Por conseguinte, a carga horária se interliga à sobrevivência, programação financeira, sentimento de valorização do trabalho desenvolvido e motivação para novas formas de atuação. No caso dos psicólogos que experimentam tamanho descompasso entre cobranças e recompensas, o mínimo que se poderia esperar é que tivessem outras atividades, em paralelo, para complementar seu salário. A carga horária incompatível com as atribuições justifica uma outra dificuldade mencionada, a evidente carência de interação do psicólogo escolar com a família dos alunos. Os pesquisados sabem da importância de trabalhar em parceria com os familiares, mas não encontram tempo suficiente para estreitarem os vínculos. Os contatos com as famílias se resumem aos momentos formais de reuniões pedagógicas, palestras e atendimentos de orientação.

Finalmente, uma última dificuldade elucidada, discutida no final, não por ser a menos dolorosa, mas talvez por desencadear boa parte das que já foram ditas anteriormente, é a formação insuficiente para atender às solicitações. Esta problemática já fora identificada na pesquisa 
desenvolvida por Yamamoto, Spinelli e Carvalho (1996) com psicólogos escolares em Natal. Há uma década já evidenciavam dificuldades relativas à identidade profissional, materializando-se em práticas individualizadas, consequência de uma formação eminentemente voltada para a clínica. É certo que o estudo a que nos referimos fora feito de forma mais abrangente, uma vez que identificou, praticamente, todas as escolas em que atuavam psicólogo escolar.

Agora, após 10 anos do estudo a que nos referimos, a amostra, com a qual trabalhamos, não registra grandes alterações de cenário, ou seja, a despeito de avanços nas práticas desenvolvidas, como o maior envolvimento com as ações pedagógicas e a preocupação com a formação de professores e ações coletivas, ainda há resquícios de indefinição profissional. Se, por um lado, os psicólogos revelam ter consciência da importância de se trabalhar, predominantemente, na perspectiva coletiva e social, as instituições ainda cobram uma atuação voltada para o individual. E, no que diz respeito à formação recebida, o cenário permanece inalterado, a ênfase para a clínica ainda é muito forte. Dos 15 participantes do estudo, apenas três não se queixaram da formação recebida durante a graduação. Deste grupo, mais da metade buscou especialização na área escolar, e outros continuam se especializando na área clínica, pois é à clínica que dedicam a maior parte de seu tempo.

\section{CONSIDERAÇÕES FINAIS}

Desenvolver a pesquisa enquanto os alunos cursavam a disciplina Psicologia e Educação foi uma experiência que articulou ensino com pesquisa. Embora a proposição do trabalho tenha partido de uma disciplina, os alunos tiveram oportunidade de integrar os conhecimentos adquiridos nas diversas disciplinas, uma vez que, na realização do trabalho, foi preciso resgatar o que estudaram em metodologia de pesquisa, práticas integrativas, história da Psicologia, Psicologia e educação, e medidas de avaliação psicológica. A interface entre essas disciplinas contribuiu para configurar o estudo, como também permitiu a compreensão da importância de saber articular os conhecimentos para melhor compreender e interferir na realidade.
As práticas que vêm sendo desenvolvidas pelos psicólogos escolares em Natal, bem como em outros estados do Brasil, revelam a necessidade de integrar os conhecimentos como forma de assegurar uma prática mais fundamentada e capaz de responder às necessidades emergentes.

A rigor, consideramos que a finalização deste estudo não poderia acontecer sem o enaltecimento da experiência de um trabalho em parceria. Almejamos que essa ideia possa continuar sendo empreendida tanto pelos professores do Curso de Psicologia da FARN, como pelos docentes de outros cursos que acreditam na importância do diálogo interdisciplinar e na pesquisa como princípio formativo.

Para os alunos, fica o aprendizado por terem articulado os conhecimentos de várias disciplinas na consecução de uma só investigação. Essa necessidade foi revelada através dos dados que conseguiram coletar, ou seja, na prática profissional, o psicólogo também precisa ser capaz de integrar os conhecimentos para melhor intervir na realidade.

O estudo evidenciou que em Natal, a despeito de tantas barreiras, o psicólogo escolar vê se configurando, de forma gradativa, o seu espaço. Isto vem ocorrendo através da participação de equipe interdisciplinar, nos projetos de integração dos alunos com alguma limitação na aprendizagem, em que a atuação do psicólogo vai além dos limites da escola, considerando, para tanto, o entorno social e familiar.

Apesar desse avanço, há de se fazer uma ressalva concernente à formação acadêmica do psicólogo escolar, considerada insuficiente para fazer face aos reclames existentes no universo onde ele vai desenvolver suas práticas educativas.

Portanto, um fator bastante positivo neste estudo foi a constatação de que o psicólogo escolar está em movimento; não fica estagnado, acomodado diante da realidade em que vive. A pesquisa trouxe, além da identificação da atuação desse profissional, o incentivo à agregação de novos conhecimentos, calcados numa sólida base teórica, objetivando alicerçar todo o arcabouço que delineia a Psicologia escolar.

Enfim, todo profissional que não investir na sua qualificação e desconsiderar a dinâmica que move o mundo ficará "mumificado" e perderá toda e qualquer chance de ser agente de transformação, bem como de colaborar para a quebra de paradigmas que estão em descompasso com os avanços e as conquistas da sociedade do conhecimento. 


\section{REFERÊNCIAS}

Almeida, M. C. (2001). Educação: Saberes e desafios. Trilhar - Revista de Ciências Humanas e Educação, 2(1), 21-27.

Correia, M., \& Campos, H. R. (2004). Psicologia escolar: História, tendências e possibilidades. In O. H. Yamamoto, \& A. C. Neto (Org.). O psicólogo e a escola: Uma introdução ao estudo da psicologia escolar (pp. 137-185). Natal: EDUFRN.

Dejours, C. (1992). A loucura do trabalho: Estudo de psicopatologia do trabalho. São Paulo: Cortez-Oboré.

Del Prette, Z. A. P., \& Del Prette, A. (2001). Habilidades envolvidas na atuação do psicólogo escolar $\backslash$ educacional. In S. M. Weschsler. Psicologia escolar: Pesquisa, formação e prática (pp. 139-156). Campinas: Alínea.

Morin, E. (2000). A cabeça bem-feita: Repensar a reforma, reformar o pensamento. Rio de Janeiro: Bertrand Brasil.

Morin, E. (2003). Educar na era planetária: O pensamento complexo como método de aprendizagem no erro e na incerteza humana. São Paulo: Cortez; Brasília, DF: UNESCO.
Pfromm Netto, S. (2001). As origens e o desenvolvimento da psicologia escolar. In S. M. Wechsler. (Org.). Psicologia escolar: Pesquisa, formação e prática (pp. 21-38). Campinas: Alínea.

Picado, L. (2005). Ansiedade da profissão docente. Mangualde: Pedago.

Novaes, M. H. (2001). Perspectivas para o futuro da psicologia escolar. In S. M. Wechsler (Org.). Psicologia escolar: Pesquisa, formação e prática (pp. 61-71). Campinas: Alínea.

Salvador, C. C. (2000). A psicologia do ensino e as práticas educativas escolares. In C. C. Salvador, I. G. Alemany, E. Martí, T. M. Majós, M. M. Mestres, J. O. Goñi et al. Psicologia do ensino (pp. 39-52). Porto Alegre: Artes Médicas do Sul.

Yamamoto, O. H., Spinelli, S., \& Carvalho, D. (1996). O psicólogo escolar em Natal: em busca de uma identidade profissional. Psicologia: Reflexão e Crítica, 9(2), 13-26.
Recebido: 05/12/2008 Received: 12/05/2008

Aprovado: 10/01/2009 Approved: 01/10/2009

Revisado: 18/09/2009 Reviewed: 09/18/2009 